\title{
Esomeprazole and aspirin fixed combination for the prevention of cardiovascular events
}

\author{
This article was published in the following Dove Press journal: \\ Vascular Health and Risk Management \\ 15 May 2013 \\ Number of times this article has been viewed
}

\author{
Katelyn W Sylvester' \\ Judy WM Cheng 1,3 \\ Mandeep R Mehra ${ }^{2,4}$ \\ 'Department of Pharmacy, \\ ${ }^{2}$ Department of Medicine, Brigham \\ and Women's Hospital, Boston, \\ MA, USA; ${ }^{3}$ Massachusetts College \\ of Pharmacy and Health Sciences, \\ Boston, MA, ${ }^{4}$ Harvard Medical School, \\ Boston MA, USA
}

\begin{abstract}
Low dose aspirin therapy plays a fundamental role in both the primary and secondary prevention of cardiovascular events. Although the evidence using low dose aspirin for secondary prevention is well-established, the decision to use aspirin for primary prevention is based on an evaluation of the patient's risk of cardiovascular events compared to their risk of adverse events, such as bleeding. In addition to the risk of bleeding associated with long term aspirin administration, upper gastrointestinal side effects, such as dyspepsia often lead to discontinuation of therapy, which places patients at an increased risk for cardiovascular events. One option to mitigate adverse events and increase adherence is the addition of esomeprazole to the medication regimen. This review article provides an evaluation of the literature on the concomitant use of aspirin and esomeprazole available through February 2013. The efficacy, safety, tolerability, cost effectiveness, and patient quality of life of this regimen is discussed. A summary of the pharmacokinetic and pharmacodynamic interactions between aspirin and esomeprazole, as well as other commonly used cardiovascular medications are also reviewed. The addition of esomeprazole to low dose aspirin therapy in patients at high risk of developing gastric ulcers for the prevention of cardiovascular disease, significantly reduced their risk of ulcer development. Pharmacokinetic and pharmacodynamic studies suggested that esomeprazole did not affect the pharmacokinetic parameters or the antiplatelet effects of aspirin. Therefore, for those patients who are at a high risk of developing a gastrointestinal ulcer, the benefit of adding esomeprazole likely outweighs the risks of longer term proton pump inhibitor use, and the combination can be recommended. Administering the two agents separately may also be more economical. On the other hand, for those patients at lower risk of developing a gastrointestinal ulcer, both the additional risk and cost make the inclusion of a proton pump inhibitor unwarranted.
\end{abstract}

Keywords: aspirin, esomeprazole, proton pump inhibitors, cardiovascular event prevention

\section{Introduction}

Cardiovascular disease is the number one cause of mortality and morbidity in the United States (US). An estimated 82.6 million Americans have one or more types of cardiovascular disease. ${ }^{1}$ Among them, 16.3 million have coronary heart disease (CHD). ${ }^{1}$ Low dose aspirin (75-325 mg per day) use is associated with a significant reduction in the risk for cardiovascular events. ${ }^{2,3}$ The role of low dose aspirin for secondary prevention (in individuals with coronary artery disease, peripheral vascular disease, or cerebrovascular disease) of cardiovascular events is well established, while its use in primary prevention is more controversial. ${ }^{4,5}$ The decision for aspirin use as primary prevention therapy is dependent on a balance of an individual's risk of cardiovascular events and adverse treatment effects, such as bleeding. ${ }^{6}$ Odd ratios for bleeding, in
Correspondence: Mandeep R Mehra Brigham and Women's Hospital, 75 Francis Street PBB A 324 Boston 021I5, MA, USA

Email mmehra@partners.org 
case-control studies of low dose aspirin use, range between 1.3-3.2. ${ }^{7}$ The US Food and Drug Administration (FDA) has not been adequately persuaded that there is sufficient evidence of a net benefit for aspirin use in primary prevention. ${ }^{8}$ The American Heart Association (AHA), however, recommends low dose aspirin in individuals with an estimated $\geq 10 \%$ risk of a cardiovascular event over a 10 -year period. ${ }^{9}$ Similarly, the US Preventive Services Taskforce (USPSTF) recommends aspirin in men aged 45-79 years in whom the benefit of a reduction in myocardial infarction (MI) outweighs the harm of an increased risk of gastrointestinal bleeding, and in women aged 55-79 years in whom the benefit of a reduction in the risk of ischemic stroke outweighs the same risk of harm. ${ }^{10}$ For older adults, they recommend a $12 \%$ risk of a cardiovascular event over 10 years as the cut-off when the benefit exceeds the risk in those aged 70-79 years. For people with diabetes, the American Diabetes Association (ADA) acknowledges the lack of a clear role for aspirin in primary prevention, and currently recommends its use in patients with diabetes who have a 10-year cardiovascular disease risk of over $10 \%{ }^{11,12}$

Although tolerable to most patients, the impact of adverse effects associated with a long-term aspirin regimen is not negligible, especially given the large number of subjects under aspirin treatment worldwide and the long term duration of therapy. Keeping patients with high cardiovascular risk on low dose aspirin therapy is an important part of cardiovascular risk management. Indeed, poor compliance has been associated with adverse cardiovascular outcomes. ${ }^{13,14}$ Discontinuation of low dose aspirin has been reported to significantly increase death, MI, stroke, and major adverse $\mathrm{CV}$ events, in a meta-analysis of six prospective studies comprising more than 50,000 patients at risk for coronary artery disease. ${ }^{15}$ The extent and reasons for noncompliance and inappropriate discontinuation of low dose aspirin therapy are not completely understood. However, adverse gastrointestinal symptoms, coronary artery disease, older age, female gender, and lower educational level have been associated with a lower level of adherence. ${ }^{16,17}$

While some factors that can cause nonadherence to aspirin therapy may not be amendable, improvement of gastrointestinal intolerance and bleeding may be one of the ways to improve compliance. There are multiple strategies that have been used to mitigate the adverse gastrointestinal effects of low dose aspirin, such as adding a gastroprotective agent that may include either a mucosal protectant, such as misoprostol or an acid suppressive agent such as an H2-receptor antagonist or a proton pump inhibitor and eradicating Helicobacter pylori. ${ }^{18}$ Switching to an alternative antiplatelet agent, such as clopidogrel, has also been recommended to prevent cardiovascular events. ${ }^{19}$ However, this strategy is not applicable to the many patients who require dual antiplatelet therapy due to an acute coronary syndrome event or who have had coronary stents placed. Proton pump inhibitors reduce the risk of aspirin-induced ulcer bleeding by up to 10 -fold. ${ }^{20,21}$ They have also been demonstrated to be superior to H2-receptor antagonists in preventing upper gastrointestinal bleeding in patients with acute coronary syndrome. ${ }^{22}$ Combination therapy with proton pump inhibitors has been advocated for patients at high risk for ulcer bleeding who are taking aspirin and other nonsteroid anti-inflammatory agents (NSAIDS). ${ }^{23,24}$ Patients considered to be at high risk for ulcer bleeding are those who have had a previous ulcer event, age $>65$ years, patients receiving concomitant anticoagulation or corticosteroid therapy, patients on low dose aspirin therapy for vascular prophylaxis, and those with severe rheumatoid arthritis requiring high doses of NSAIDs. Despite these recommendations, cotherapy with proton pump inhibitors or H2-antagonists for the prevention of low dose aspirin-related gastrointestinal adverse events in patients with a history of peptic ulcer disease is often under prescribed. Based on a drug utilization study of 30,015 aspirin prescriptions, coprescribing of aspirin and proton pump inhibitors or H2-antagonists occurred only $3.46 \%$ of the time..$^{25} \mathrm{~A}$ single, fixed dose capsule combining low dose aspirin with the proton pump inhibitor esomeprazole (Axanum ${ }^{\circledR}$ formulated as enteric coated pellets) has been developed and approved in the European Union to reduce the risk of gastric and/or duodenal (peptic) ulcers and to potentially improve patient adherence. The fixed dose capsule contains aspirin $81 \mathrm{mg}$ and esomeprazole $20 \mathrm{mg}{ }^{26}$ This article reviews the pharmacological properties, clinical efficacy and tolerability of low dose aspirin/esomeprazole in patients requiring low dose aspirin therapy who are at risk of aspirin associated peptic ulcers.

\section{Methodology}

Peer-reviewed clinical trials, review articles, and relevant treatment guidelines, published in English and relating to human (not animal), were identified from MEDLINE and Current Content database (both January 1, 1966 to February 1, 2013) using search terms aspirin, esomeprazole, proton pump inhibitors, pharmacology, pharmacokinetics, pharmacodynamics, pharmacoeconomics, and cost-effectiveness and were evaluated. This revealed 14 total articles, including four review articles and seven clinical trials (including pharmacokinetics and 
pharmacodynamics study). Review articles are not discussed in this review as we are focusing on clinical implications.

\section{Pharmacokinetics and pharmacodynamics}

Pharmacokinetic and pharmacodynamic studies are important to identify drug-drug interactions with the coadministration of low dose aspirin and proton pump inhibitors to ensure that while providing gastric protection, the addition of a proton pump inhibitor does not decrease the cardiovascular protective effects of aspirin. A pharmacokinetic evaluation was conducted with 55 male and female healthy volunteers (mean age 27.1 years, mean body mass index [BMI] $23 \mathrm{~kg} / \mathrm{m}^{2}$ ) who were randomized in an open 3-way crossover study to receive either uncoated aspirin $325 \mathrm{mg}$ alone, esomeprazole $40 \mathrm{mg}$ alone, or the combination of the two drugs (in separate tablet/capsules) for 5 days separated by at least a 13 day washout period..$^{27}$ There were no significant pharmacokinetic interactions observed after repeated coadministration. The $90 \%$ confidence intervals for the geometric means of the steady-state area under the plasma concentration-time curve during the dosing interval (AUCi) and the observed maximum plasma concentration $\left(\mathrm{C}_{\max }\right)$ ratios were within the predefined bioequivalence interval of $80 \%$ to $125 \%$ when comparing aspirin alone with aspirin plus esomeprazole as well as when comparing esomeprazole alone with esomeprazole plus aspirin. The time to $\mathrm{C}_{\max }\left(\mathrm{t}_{\max }\right)$ and the terminal half-life $\left(t_{1 / 2}\right)$ were also similar for each agent individually and in combination.

The bioequivalence of uncoated aspirin $325 \mathrm{mg}$ and esomeprazole $40 \mathrm{mg}$ administered as individual components compared to a single-capsule formulation was also evaluated in an open-label, randomized, 2-way crossover study of 49 male and female healthy volunteers (mean age 28 years, mean BMI $\left.24.1 \mathrm{~kg} / \mathrm{m}^{2}\right) .{ }^{28}$ Each participant received a single dose of the treatment regimen followed by at least a 6-day washout period. The two therapies were considered to be bioequivalent if the $94 \%$ confidence interval of the geometric mean ratios of AUC and $\mathrm{C}_{\max }$ were within the predefined interval of $80 \%$ to $125 \%$. The study results confirmed bioequivalence and also demonstrated similar kinetics for $t_{\text {max }}$ and $t_{1 / 2}$.

Both of these studies used higher doses than those manufactured in the fixed dose combination capsule in an attempt to maximize the possibility of finding an interaction between the two drugs. Additionally, generalizability may be limited to the general population since both of these studies utilized the uncoated aspirin tablets which may not be a true reflection of clinical practice, as those patients at high risk of a gastrointestinal complication are likely to be taking either buffered aspirin or enteric coated aspirin. Of note, similar pharmacokinetic studies have been performed using omeprazole as the proton pump inhibitor of choice, and results from those studies showed no clinically significant difference in bioavailability when omeprazole was administered with uncoated aspirin and enteric-coated aspirin..$^{29}$

Although the above studies suggest that there is no pharmacokinetic interaction between the two agents when coadministered either in a fixed dose capsule or concomitantly as individual drugs, there is some retrospective data to suggest that a pharmacodynamic interaction may exist between aspirin and proton pump inhibitors in terms of a reduction in the antiplatelet action of aspirin. This has not been confirmed by prospective studies. ${ }^{30-32} \mathrm{~A}$ recent study by Andersson et al randomized 29 male and female healthy volunteers (mean age 50 years, mean BMI $26 \mathrm{~kg} / \mathrm{m}^{2}$ ) in an open-label 2-way crossover study to either aspirin $81 \mathrm{mg}$ for 5 days or esomeprazole $20 \mathrm{mg}$ in combination with aspirin $81 \mathrm{mg}$ for 5 days with at least a 14-day washout period. ${ }^{33} \mathrm{~A}$ pharmacodynamic interaction was evaluated by assessing the relative change in aspirin reactivity units using the VerifyNow (Accumetrics, San Diego, CA, USA) aspirin assay after 5 days of treatment versus baseline. No pharmacodynamic interactions were observed based the geometric mean ratio of day six to baseline aspirin reactivity unit values. There was also no difference in the secondary endpoint of suppression of serum thromboxane B2.

\section{Efficacy}

There have been no published clinical trials evaluating the efficacy of a fixed combination of esomeprazole and aspirin for the prevention of cardiovascular events. There have been, however, two randomized, double-blind, multinational, placebo-controlled clinical trials that evaluated the occurrence of peptic ulcers when esomeprazole was administered to patients at risk of developing ulcers while taking low dose aspirin (75-325 mg) for 26 weeks. ${ }^{34,35}$ The primary efficacy endpoint for both studies was the occurrence of an endoscopy confirmed gastric and/or duodenal ulcer and mucosal break of at least $3 \mathrm{~mm}$.

The Efficacy of esomprazole ( $20 \mathrm{mg}$ once daily) for reducing the risk of gastrointestinal ulcers associated with continuous use of low-dose aspirin (ASTERIX) study included patients who were at moderate to high risk of developing a peptic ulcer (defined as being $\geq 60$ years old and having a negative $H$. pylori test with no evidence of a peptic ulcer at baseline) and required continuous low dose aspirin for secondary prevention of cardiovascular events. ${ }^{34}$ Patients were then randomized in a 1:1 ratio to either esomeprazole $20 \mathrm{mg}$ or placebo in addition to their baseline aspirin 
regimen. Secondary efficacy outcomes included esophageal ulcers and upper gastrointestinal symptoms assessed by the investigators.

Results from the intention-to-treat population $(\mathrm{n}=991)$ showed a $71 \%$ relative risk reduction in ulcer development when taking esomeprazole $20 \mathrm{mg}$ compared to placebo. During the 26-week study period, 27 patients $(5.4 \%)$ in the placebo group developed either a gastric or duodenal ulcer and 8 patients $(1.6 \%)$ in the esomeprazole group developed a peptic ulcer $(P=0.0007$ for life-table estimated at 6 months); this difference was evident as early as 8 weeks into the study $(P=0.0061)$. The median ulcer size in both groups was $7 \mathrm{~mm}$. Only one patient in each group had an ulcer greater than $10 \mathrm{~mm}$ and there were no gastric or duodenal ulcers less than $5 \mathrm{~mm}$ detected in the esomeprazole group (compared to 6 ulcers less than $5 \mathrm{~mm}$ in the placebo group). The difference in outcomes was most evident for those patients who developed an ulcer that was $5-10 \mathrm{~mm}$ in size, which occurred in 20 patients in the placebo group, and 7 patients in the esomeprazole group. Erosive esophagitis was also lower in the esomeprazole group versus the placebo group $(P<0.001)$. The development of epigastric burning and heartburn was significantly decreased with the addition of esomeprazole $(P<0.05)$, but it had no effect on other upper gastrointestinal symptoms such as epigastric pain and discomfort, acid regurgitation, nausea, or vomiting.

The OBERON study (Prevention of peptic ulcers with esomeprazole in patients at risk of ulcer development treated with low-dose acetylsalicylic acid: a randomized, controlled trial) evaluated patients whose doctor prescribed or recommended daily low dose aspirin and included patients on aspirin for both primary and secondary prevention, who were $H$. pylori negative and who were at high risk of developing a peptic ulcer (defined as age $\geq 18$ years old with a documented history of an uncomplicated peptic ulcer, age $\geq 60$ years with one or more risk factors for a peptic ulcer, or aged $\geq 65$ years). ${ }^{35}$ Patients were then randomized in a $1: 1: 1$ ratio to esomeprazole $20 \mathrm{mg}$, esomeprazole $40 \mathrm{mg}$, or placebo in addition to their baseline aspirin regimen.

This study resulted in an $85 \%$ relative risk reduction in ulcer development for patients taking esomeprazole $40 \mathrm{mg}$ (1.5\%) compared to those taking placebo (7.4\%) and an $80 \%$ reduction in those taking esomeprazole $20 \mathrm{mg}(1.1 \%)$ compared with those taking placebo in the intention-totreat population $(n=2426)$. The absolute risk reduction was $6.3 \%$ in the esomeprazole $40 \mathrm{mg}$ group and $5.9 \%$ in the esomeprazole $20 \mathrm{mg}$ group. This study did not evaluate gastrointestinal symptoms and did not report on ulcer size.
Both studies found that gastric ulcers were more prevalent than duodenal ulcers in all treatment groups. Additionally, posthoc analyses in both studies showed that esomeprazole significantly decreased ulcer occurrence regardless of the dose of aspirin used (75-100 mg versus 101-325 mg). In both trials, compliance was assessed for the study drugs only (esomeprazole and placebo, not aspirin) and patients were considered to be compliant if they took their doses at least $75 \%$ of the time (ASTERIX compliance rates were around $85 \%$ and for OBERON compliance rates were around 94\%). Compliance with aspirin was not evaluated in either of these studies. It is not known if coadministration with esomeprazole will enhance aspirin adherence.

Overall, the results from these studies demonstrated that for patients requiring continuous low dose aspirin for primary or secondary prevention of cardiovascular events who are at moderate to high risk of developing a peptic ulcer, administration of esomeprazole reduces the development of peptic ulcers. Additionally the OBERON trial showed that treatment with either esomeprazole $20 \mathrm{mg}$ or $40 \mathrm{mg}$ is equally efficacious. It is important to note that these patients were only followed up for 26 weeks whereas the typical patient on low dose aspirin therapy would require lifetime treatment. Additionally, ulcers were identified using endoscopy, which also may not be reflective of clinical practice.

\section{Safety and tolerability}

The ASTERIX and OBERON studies found that taking esomeprazole along with their current low dose aspirin regimen was well tolerated by patients. In the ASTERIX study, there were six bleeding events: four in the placebo group and two in the esomeprazole group. Both of the patients in the esomeprazole group had a bleed related to a preexisting ulcer history, whereas none of the patients in the placebo group had a history of ulcers. In the OBERON study, there were five bleeding events: two in the esomeprazole $20 \mathrm{mg}$ group, three in the placebo group, and none in the esomeprazole $40 \mathrm{mg}$ group; no additional information was provided on the patients' prior risk for developing a bleeding event.

In each of the three treatment groups of the OBERON study, $37 \%$ of patients experienced an adverse event. Fatal serious adverse events accounted for $\leq 0.5 \%$ of the total events and nonfatal serious adverse events accounted for another $5 \%$. Although there were nine deaths in the study, with eight deaths in the esomeprazole treatment group, none of the deaths were found to be related to study drug administration. A cardiacrelated cause was responsible for five of the nine deaths (myocardial infarction, $\mathrm{n}=2$ [one esomeprazole $40 \mathrm{mg}$ and one placebo recipient $]$ ), cerebrovascular accident $(n=1$, esome- 
prazole $20 \mathrm{mg}$ ), cardiac arrest $(\mathrm{n}=1$, esomeprazole $20 \mathrm{mg}$ ), acute coronary syndrome $(\mathrm{n}=1$, esomeprazole $20 \mathrm{mg})$, sudden death ( $\mathrm{n}=1$, esomeprazole $40 \mathrm{mg}$ ). Adverse events leading to withdrawal of treatment occurred in $3.7 \%$ of the patients in the esomeprazole $40 \mathrm{mg}$ group, $4.6 \%$ of the patients in the esomeprazole $20 \mathrm{mg}$ group, and $5.2 \%$ of those in the placebo group. Treatment related adverse events occurred in $4.2 \%$ of the patients in the esomeprazole $40 \mathrm{mg}$ group, $4.9 \%$ of the patients in the esomeprazole $20 \mathrm{mg}$ group, and $3.9 \%$ of those in the placebo group. The most common adverse events included gastrointestinal symptoms (diarrhea, nausea, upper abdominal pain, constipation, dyspepsia), headache, dizziness, respiratory complications (bronchitis, influenza, nasopharyngitis, upper respiratory infections), back pain, urinary tract infections, and hypertension. All of these events occurred in less than $4 \%$ of the population. Overall, about $2.5 \%$ of the adverse events were categorized as cardiac disorders with no clinically significant differences between the treatment groups.

The ASTERIX study investigators found that $7 \%$ of patients $(n=69)$ had a serious adverse event. Unlike the OBERON study, the most common serious adverse events were cardiac disorders, which accounted for approximately $32 \%$ of all serious adverse events reported ( 8 and 14 patients, respectively, in the esomeprazole and placebo groups). Three patients in the placebo group experienced myocardial infarction and there were no such events in the esomeprazole group. Adverse events led to withdrawal of treatment in 45 patients, $3.9 \%$ of the patients in the esomeprazole group and $5.2 \%$ of those in the placebo group. No other complications were reported by the study investigators.

Results from these two trials suggest that esomeprazole in combination with low dose aspirin was well tolerated and raised no significant safety concerns. The safety profile of long-term proton pump inhibitor use must also be considered in the risk versus benefit analysis for prophylaxis of peptic ulcers associated with low dose aspirin use. Epidemiological data have suggested that there may be an increased risk of vertebral and hip fractures with chronic proton pump inhibitor use. ${ }^{36-40}$ The reduction in gastric acid by proton pump inhibitors may also serve as an important risk factor for infection with acidlabile bacteria, such as Clostridium difficile and pneumonia, and prevent absorption of key nutrients (Table 1)..$^{41-45}$

\section{Potential interaction between esomeprazole and other cardiovascular medications}

Although esomeprazole reduced incidence of peptic ulcer in patients who received chronic aspirin therapy for primary or
Table I Potential long-term adverse effect of proton pump inhibitors $^{36-45}$

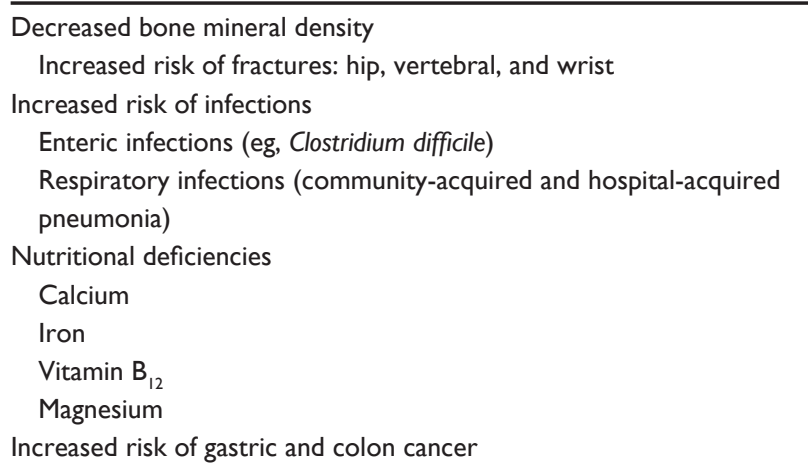

secondary prevention in cardiovascular diseases, in order to decide if esomeprazole should be routinely added to aspirin therapy, it is also important to consider other potential drug interactions that esomeprazole may have with other medications that are commonly prescribed to patients with cardiovascular diseases.

Similar to many other proton pump inhibitors, esomeprazole is metabolized by cytochrome $\mathrm{P} 4502 \mathrm{C} 19$, and it also has the ability to inhibit the same enzyme. ${ }^{46}$ Clopidogrel and aspirin are commonly used together in patients with coronary artery diseases. Clopidogrel is an antiplatelet agent that requires cytochrome P450 2C19 enzyme to convert to its pharmacologically active form. There has been considerable controversy regarding the risk of cardiovascular events from the potential interaction between clopidogrel and proton pump inhibitors, including esomeprazole. ${ }^{47-49}$ In 2009, the FDA released warnings specifically against the concomitant use of omeprazole or esomeprazole with clopidogrel based on pharmacokinetic and platelet function data. ${ }^{50}$ However, the FDA also stated that they did not have sufficient information on the impact of other proton pump inhibitors. Nevertheless, it has been suggested that pantoprazole may be a safer option than omeprazole, based on clinical trial data demonstrating that omeprazole significantly affected the antiplatelet effect of clopidogrel, whereas pantoprazole did not. Given the multitude of platelet function tests, extent of individual variability and complexity of the platelet regulation pathways, the consistency of the entire dataset should be considered before deciding on one proton pump inhibitor over another. A recent systematic review was performed including 18 platelet function studies as well as 33 clinical studies in patients with acute coronary syndrome or undergoing percutaneous coronary intervention. ${ }^{51}$ In $70 \%$ of the laboratory studies, antiplatelet activity of clopidogrel was reduced by concomitant use of proton 
pump inhibitors. The 33 clinical studies showed significant heterogeneity in observed outcomes, with risk ratios for major adverse cardiovascular events varying from 0.64 to 4.58 when proton pump inhibitors are used together with clopidogrel. The investigators stated that the result could not substantiate an adverse effect of proton pump inhibitor used on clinical outcome in patients on clopidogrel.

Because esomeprazole inhibits stomach acid production and increases gastric $\mathrm{pH}$, it may interfere with drugs for which gastric $\mathrm{pH}$ affects bioavailability. Digoxin absorption from the gastrointestinal tract is enhanced by the presence of gastric acid. When esomeprazole is coadministered with digoxin, reduced acidity may compromise digoxin absorption, thus decreasing its bioavailability. Therefore, monitoring the patient for digoxin efficacy should be considered if esomeprazole is being used concurrently with digoxin. ${ }^{52}$

\section{Cost effectiveness}

Although trial data have led to strong recommendations for the use of aspirin as a secondary prevention strategy, the data are less clear for the use of aspirin for primary prevention because the lower baseline risk of myocardial infarction may or may not balance out the increased risk of both hemorrhagic stroke and gastrointestinal bleeding. In these scenarios, a Framingham risk score is usually calculated to determine the 10-year risk of coronary heart disease and that risk is weighed against patients' predisposing risk factors for developing an aspirin related bleeding event. In either scenario, adherence to daily aspirin therapy is imperative to ensure the cardiovascular benefits are realized. Studies have shown that as many as $30 \%$ of patients are not fully adherent to aspirin therapy with aspirin related dyspepsia being cited one of the main reasons for discontinuing therapy. ${ }^{16,17}$ From the patients' perspective, daily aspirin therapy may be associated with a decrease in their quality of life and the daily dyspepsia symptoms may overshadow the more remote, but acute risks of a myocardial infarction. If this perception leads to discontinuation of therapy, with or without the providers' knowledge, it poses an increased risk of mortality. ${ }^{15}$

Several cost-utility and cost-effectiveness studies have been conducted to determine if dual preventative therapy with aspirin and a proton pump inhibitor results in increased patient adherence and satisfaction, increased quality-adjusted life years and if the therapy is cost-effective when compared to no therapy or aspirin alone. ${ }^{53-55} \mathrm{~A}$ cost-utility analysis examined the use of aspirin with and without the addition of a proton pump inhibitor for primary cardiovascular disease prevention in men with a range of different coronary heart disease and gastrointestinal bleeding risks. ${ }^{54}$ Based on their model, they found that men taking aspirin in addition to a proton pump inhibitor gained more quality-adjusted-life-years (18.67 versus 18.68), but also incurred higher costs (US \$21,037 versus US \$17,571) over their remaining lifetime. The incremental cost per quality-adjusted-life-years of US $\$ 447,077$ suggested that for a 45 -year old man with a 10 -year, 10\% CHD risk and average bleeding risk (defined as a risk of gastrointestinal bleeding mortality of 1 in 1000 patients), the addition of a proton pump inhibitor was not cost-effective. These results remained consistent across all CHD risk levels and for men 55 and 65 years old. The authors also tested their results against varied baseline bleeding risks. When the baseline bleeding risk increased to 4 in 1000 patients, the incremental cost per quality-adjusted lifeyear was less than US \$50,000 annually and became cost-effective when the risk was increased to 7 in 1000 patients. For men greater than 55 years old, the incremental cost per quality-adjusted-life-years for prophylactic treatment with a proton pump inhibitor was less than US \$50,000 annually when the bleeding risk was increased to 2 or 3 per 1000 patients. Overall, the investigators found that adding a generic proton pump inhibitor for all men is not cost effective due to the relatively small risk of gastrointestinal bleeding. For men with an increased risk of bleeding, the addition of a proton pump inhibitor may be cost effective.

Two cost-effectiveness studies were conducted by Saini et al. The first study evaluated the benefit of proton pump inhibitors on reduction in upper gastrointestinal bleeding risk for patients taking low dose aspirin for secondary prevention. ${ }^{54}$ They assumed an annual cost of a generic proton pump inhibitor therapy to be US $\$ 250$, average age was 65 years old, and average bleeding risk to be 2.5 in 1000 patients. Results from their base case analysis showed that coadministration of a proton pump inhibitor is cost-effective; however, it was not cost-effective in younger patients. The second study modified their previous model to take into account aspirin discontinuation due to dyspepsia and the effect on cardiovascular events. ${ }^{55}$ The base-case in this study assumed a patient aged 50-years old, taking low dose aspirin for secondary prevention with no risk factors for upper gastrointestinal bleeding ( 5 in 1000 patients at age 65), assuming the annual cost of generic proton pump inhibitor therapy to be US \$144. They estimated the absolute increase in adherence to aspirin therapy when coadministered with a proton pump inhibitor to be $2.5 \%$ when using published data that $20 \%$ of patients will discontinue aspirin therapy at 1 -year and $25 \%-40 \%$ will discontinue by 5 years. Compared to aspirin alone, the addition of a proton 
pump inhibitor led to fewer upper gastrointestinal bleeding events, increased aspirin adherence and fewer recurrent MIs resulting in 38 additional days of life per patient. Much of this benefit was due to a reduction in cardiovascular mortality. The incremental cost-effectiveness ratio was US $\$ 19,000$ per life-year saved.

\section{Discussion and conclusion}

Clinical studies have demonstrated that the addition of esomeprazole to low dose aspirin therapy in patients at high risk of developing gastric ulcers for the prevention of cardiovascular disease, significantly reduced their risk of ulcer development. There are no clinical studies performed to-date to evaluate whether the addition of esomeprazole to low dose aspirin has the same efficacy in primary or secondary prevention of cardiovascular events compared to aspirin alone. However, pharmacokinetic and pharmacodynamic studies suggested that with the addition of esomeprazole, there are no alterations in the pharmacokinetic parameters and antiplatelet effects of aspirin. All of these studies evaluated patients for a short duration. It is therefore difficult to make a definitive determination on the long-term clinical efficacy, safety, and tolerability of combination low dose aspirin and esomeprazole use in patients with cardiovascular disease.

For patients who require low dose aspirin therapy for either primary or secondary prevention of cardiovascular events (Table 2), it is clear that adherence to daily aspirin therapy is required for the mortality benefit seen in trials and that nonadherence is often due to gastrointestinal side effects (which may or may not include the development of peptic ulcers). Therefore, based on current data, for those patients who are at a high risk of developing a gastrointestinal ulcer (Table 3 ), the benefit of adding esomeprazole to prevent low dose aspirin discontinuation likely outweighs

Table 2 Summary of recommendations on aspirin use for the prevention of cardiovascular events ${ }^{10,11,56}$

\begin{tabular}{|c|c|c|}
\hline Population & Recommendation & Level of evidence \\
\hline \multicolumn{3}{|l|}{ US preventative services task force } \\
\hline Men 45-79 years old & $\begin{array}{l}\text { Encourage use of ASA* ( } 75 \mathrm{mg} / \text { day) when potential } \\
\text { benefit of a reduction in MI outweighs the potential } \\
\text { harm of an increase in GI hemorrhage }\end{array}$ & A \\
\hline Women $55-79$ years old & $\begin{array}{l}\text { Encourage use of ASA* ( } 75 \mathrm{mg} / \mathrm{day}) \text { when potential benefit } \\
\text { of a reduction in ischemic strokes outweighs the } \\
\text { potential harm of an increase in Gl hemorrhage }\end{array}$ & A \\
\hline Men and Women $>80$ years old & $\begin{array}{l}\text { Insufficient evidence to assess the balance of benefit } \\
\text { and harm for } \mathrm{CV} \text { disease prevention }\end{array}$ & I \\
\hline Women $<55$ years old and & Do not encourage the use of ASA* for CV disease prevention & $\mathrm{D}$ \\
\hline \multicolumn{3}{|l|}{ Men $<45$ years old } \\
\hline \multicolumn{2}{|c|}{ AHA/ACCF scientific statement 2010 : primary prevention } & ACCFIAHA \\
\hline $\begin{array}{l}\text { Adults with DM and a } 10 \text {-year CVD } \\
\text { risk }>10 \% \text { who are not at increased } \\
\text { risk for bleeding }\end{array}$ & Consider low dose ASA* therapy (75 to $162 \mathrm{mg} /$ day) & B \\
\hline Adults with DM and a 10 -year CVD risk $<5 \%$ & Not recommended & C \\
\hline $\begin{array}{l}\text { Adults with DM and a } 10 \text {-year CVD } \\
\text { risk of } 5 \%-10 \%\end{array}$ & $\begin{array}{l}\text { Consider using low dose ASA* (75 to } 162 \mathrm{mg} / \text { day) } \\
\text { until further research is available }\end{array}$ & C \\
\hline ADA 20 I I guidelines & & ADA \\
\hline $\begin{array}{l}\text { High CVD risk: } 10 \text {-year risk }>10 \% \\
\text { Type I and } 2 \text { DM }\end{array}$ & Type I and 2 DM & C \\
\hline Low CVD risk I0-year risk $<5 \%$ & Risk of bleed outweighs benefit; not recommended & C \\
\hline Moderate CVD risk 10-year risk 5\%-10\% & Clinical judgment of risk versus benefit required & $\mathrm{E}$ \\
\hline $\begin{array}{l}\text { Secondary prevention: all patients with } \\
\text { DM and history of CVD }\end{array}$ & Use ASA* 75-162 mg/day & A \\
\hline $\begin{array}{l}\text { Documented ASA* allergy in patients with } \\
\text { DM and h/o CVD }\end{array}$ & Use clopidogrel 75 mg/day & B \\
\hline Patients with DM and ACS & $\begin{array}{l}\text { Combination therapy with ASA* }(75-162 \mathrm{mg} / \text { day }) \text { and } \\
\text { clopidogrel } 75 \mathrm{mg} / \text { day) up to one year }\end{array}$ & B \\
\hline
\end{tabular}

Notes: ASA* is contraindicated in patients <2I years old due to the risk of Reye's syndrome. A: benefit is substantial; B: benefit is moderate; C: benefit is small; D: Harm outweighs benefit; I: Insufficient evidence. ACCF/AHA - A: data from many large, randomized controlled trials; B: data from fewer, smaller randomized controlled trials, non-randomized studies or observational registries; C: expert consensus. ADA - A: clear evidence randomized controlled trial or meta-analysis; B: supportive evidence from cohort studies; C: supportive evidence from poorly controlled or uncontrolled studies; E: expert consensus.

Abbreviations: ACCF, American College of Cardiology Fellows; ACS, acute coronary syndrome; ADA, American Diabetes Association; AHA, American Heart Association; ASA, aspirin; CVD, cardiovascular disease; DM, diabetes mellitus; GI, gastrointestinal; h/o, history of; MI, myocardial infarction. 
Table 3 Risk factors for gastrointestinal bleeding 7,18

History of gastrointestinal bleeding
Peptic ulcer disease
Upper gastrointestinal tract pain
Concomitant medications
Nonsteroidal anti-inflammatory drugs
Anticoagulants (warfarin, dabigatran, rivaroxaban, low molecular
weight heparin, fondaparinux)
Antiplatelets (clopidogrel, ticagrelor, prasugrel, ticlopidine, cilostazol,
dipyridamole)
Steroids
Advanced age
Male gender
Uncontrolled hypertension

the risks of longer term proton pump inhibitor use. In these high-risk patients, the extra cost to both the patient and the healthcare system may be justified by the reduction in associated cardiovascular mortality and the combination can be recommended. The addition of esomeprazole to a low dose aspirin regimen may be a more appropriate choice than the fixed dose combination capsule as it allows each individual medication dose to be titrated easily. In addition, giving the two agents separately may be more economical from a patient cost perspective since both medications currently have generic alternatives. Fixed dose combination therapy has the potential to further improve medication regimen adherence, but this has not been formally evaluated to determine if the benefit from improved adherence outweighs the potential increased cost of the fixed combination therapy and will have to be determined by individual patient preference. On the other hand, for those patients at lower risk of developing a gastrointestinal ulcer, both the additional risk and cost make the inclusion of a proton pump inhibitor unwarranted.

In addition, the USPSTF recommendation statement provided 10-year CHD risk levels where the number of cardiovascular disease events prevented is balanced by the number of serious bleeding events. ${ }^{10}$ They recommend that this is the point where shared decision making between the provider and patient is necessary. For these patients who would likely benefit from long term low dose aspirin therapy, the addition of a proton pump inhibitor may abrogate the increased bleeding risk. Similarly, patients who have one or more risk factors for gastrointestinal bleeding, but who have a high 10-year risk of CHD or strong family history of CHD, may also benefit from the addition of a proton pump inhibitor rather than switching to either an alternative regimen such as clopidogrel or forgoing the benefit of primary prevention with antiplatelet therapy.

\section{Disclosure}

The authors report no conflicts of interest in this work.

\section{References}

1. Roger VL, Go AS, Lloyd-Jones DM, et al; American Heart Association Statistics Committee and Stroke Statistics Subcommittee. Heart disease and stroke statistics - 2012 update: a report from the American Heart Association. Circulation. 2012;125(1):e2-e220.

2. Hennekens $\mathrm{CH}$. Aspirin in the treatment and prevention of cardiovascular disease: current perspective and future directions. Curr Atheroscler Rep. 2007;9(5):409-416.

3. Baigent C, Blackwell, L, Collins R, et al; Antithrombotic Trialists' (ATT) Collaboration. Aspirin in the primary and secondary prevention of vascular disease: collaborative meta-analysis of individual participant data from randomized trials. Lancet. 2009;373(9678):1849-1860.

4. Berger JS, Lala A, Krantz MJ, Baker, GS, Hiatt WR. Aspirin for the prevention of cardiovascular events in patients without clinical cardiovascular disease: a meta-analysis of randomized trial. Am Heart $J$. 2011;162(1):115-124.

5. Seshasai SR, Wijesuriya S, Sivakumaran R, et al. Effect of aspirin on vascular and nonvascular outcomes: meta-analysis of randomized controlled trials. Arch Intern Med. 2012;172(3):209-216.

6. Sussman JB, Vijan S, Choi H, Hayward RA. Individual and population benefits of daily aspirin therapy: a proposal for personalizing national guidelines. Cir Cardiovasc Qual Outcomes. 2011;4(3):268-275.

7. Shiotani A, Manabe N, Kamada T, Fujimura Y, Sakakibara, Haruma K. Risk and prevention factors of low-dose aspirin-induced gastroduodenal injuries: a comprehensive review. $J$ Gastroenterol Hepatol. 2012;27(Suppl 3):8-12.

8. AHA/ADA vs ESC/EASD recommendations on aspirin as a primary prevention strategy in people with diabetes: how the same data generate divergent conclusions. Eur Heart J. 2007;28(16):1925-1927.

9. Pearson TA, Blair SN, Daniels SR, et al. AHA Guidelines for Primary Prevention of Cardiovascular Disease and Stroke: 2002 Update: consensus panel guide to comprehensive risk reduction for adult patients without coronary or other atherosclerotic vascular diseases. American Heart Association Science Advisory and Coordinating Committee. Circulation. 2002;106(3):388-391.

10. US Preventive Services Task Force. Aspirin for the prevention of cardiovascular disease: US Preventive Services Task Force recommendation statement. Ann Intern Med. 2009;150(6): 396-404.

11. Pignone M, Alberts MJ, Colwell JA, et al; American Diabetes Association; American Heart Association; American College of Cardiology Foundation. Aspirin for primary prevention of cardiovascular events in people with diabetes: a position statement of the American Diabetes Association, a scientific statement of the American Heart Association, and an expert consensus document of the American College of Cardiology Foundation. Diabetes Care. 2010; 33(6): 1395-1402.

12. Pignone M, Williams CD. Aspirin for primary prevention of cardiovascular disease in diabetes mellitus. Nat Rev Endocrinol. 2010;6(11): 619-628.

13. Chen WH, Cheng X, Lee PY, et al. Aspirin resistance and adverse clinical events in patients with coronary artery disease. Am J Med. 2007;120(7):631-635.

14. Krasopoulos G, Brister SJ, Beattie WS, Buchanan MR. Aspirin "resistance" and risk of cardiovascular morbidity: systematic review and meta-analysis. BMJ. 2008;336(7637):195-198.

15. Biondi-Zoccai GG, Lotrionte M, Agostoni P, et al. A systematic review and meta-analysis on the hazards of discontinuing or not adhering to aspirin among 50,279 patients at risk for coronary artery disease. Eur Heart J. 2006;27(22):2667-2674.

16. Kulkarni SP, Alexander KP, Lytle B, Heiss G, Peterson ED. Longterm adherence with cardiovascular drug regimens. Am Heart J. 2006; 151(1):185-191. 
17. Pratt S, Thompson VJ, Elkin EP, Næsdal J, Sörstadium E. The impact of upper gastrointestinal symptoms on nonadherence to, and discontinuation of, low-dose acetylsalicylic acid in patients with cardiovascular risk. Am J Cardiovasc Drugs. 2010;10(5):281-288.

18. Lanas A, Scheiman J. Low-dose aspirin and upper gastrointestinal damage: epidemiology, prevention and treatment. Curr Med Res Opin. 2007;23(1):163-173

19. Fihn SD, Gardin JM, Abrams J, et al; American College of Cardiology Foundation. 2012 ACCF/AHA/ACP/AATS/PCNA/SCAI/STS guideline for the diagnosis and management of patients with stable ischemic heart disease: executive summary: a report of the American College of Cardiology Foundation/American Heart Association task force on practice guidelines, and the American College of Physicians, American Association for Thoracic Surgery, Preventive Cardiovascular Nurses Association, Society for Cardiovascular Angiography and Interventions, and Society of Thoracic Surgeons. Circulation. 2012;126(25):3097-3137.

20. Lai KC, Lam SK, Chu KM, et al. Lansoprazole for the prevention of recurrences of ulcer complications from long-term low-dose aspirin use. N Engl J Med. 2002;346(26):2033-2038.

21. Chan FK, Chung SC, Suen BY, et al. Preventing recurrent upper gastrointestinal bleeding in patients with Helicobacter pylori infection who are taking low-dose aspirin or naproxen. $N$ Engl J Med. 2001; 344(13):967-973.

22. Ng FH, Tunggal P, Chu WM, et al. Esomeprazole compared with famotidine in the prevention of upper gastrointestinal bleeding in patients with acute coronary syndrome or myocardial infarction. Am J Gastroenterol. 2012;107(3):389-396.

23. Laine L. Approaches to nonsteroidal anti-inflammatory drug use in the high-risk patient. Gastroenterology. 2001;120(3):594-606.

24. Chan FK, Ching JY, Hung LC, et al. Clopidogrel versus aspirin and esomeprazole to prevent recurrent ulcer bleeding. NEngl J Med. 2005; 352(3):238-244.

25. Zhu LL, Xu LC, Chen Y, Zhou Q, Zeng S. Poor awareness of preventing aspirin-induced gastrointestinal injury with combined protective medications. World J Gastroenterol. 2012;18(24):3167-3172.

26. The pharmaletter [homepage on the Internet]. AstraZeneca gets EU approval for Axanum; Merck and Co files ridaforolimus with EMA The pharmaletter; 2011. Available from: http://www.thepharmaletter com/file/106266/astrazeneca-gets-eu-approval-for-axanum-merck-cofiles-ridaforolimus-with-ema.html. Accessed December 17, 2012.

27. Niazi M, Andersson T, Nauclér E, Sundin M, Naesdal J. Evaluation of the pharmacokinetic interaction between esomprazole $(40 \mathrm{mg})$ and acetylsalicylic acid (325 mg) in healthy volunteers. Int J Clin Pharmacol Ther. 2009;47(9):564-569.

28. Niazi M, Andersson T, Nauclér E, Næsdal J. Evaluation of bioequivalence between a single-capsule formulation of esomprazole $40 \mathrm{mg}$ and acetylsalicylic acid $325 \mathrm{mg}$ and the monotherapies given seperately in healthy volunteers. Int J Clin Pharmacol Ther. 2011;49(2): 169-176.

29. Nefesoglu FZ, Ayanoglu-Dülger G, Ulusoy NB, Imeryüz N. Interaction of omeprazole with enteric-coated salicylate tablets. Int J Clin Pharmacol Ther. 1998;36(10):549-553.

30. Charlot M, Grove EL, Hansen PR, et al. Proton pump inhibitor use and risk of adverse cardiovascular events in aspirin treated patients with first time myocardial infarction: nationwide propensity score matched study. BMJ. 2011;342:d2690.

31. Wurtz M, Grove EL, Kristensen SD, Hvas AM. The antiplatelet effect of aspirin is reduced by proton pump inhibitors in patients with coronary artery disease. Heart. 2010;96(5):368-371.

32. Adamopoulos AB, Sakizlis GN, Nasothimiou EG, et al. Do proton pump inhibitors attenuate the effect of aspirin on platelet aggregation? A randomized crossover study. J Cardiovasc Pharmacol. 2009;54(2): 163-168.

33. Andersson T, Morrison D, Nagy P, Pisupati J, Schettler J, Warner TD Evaluation of the pharmacodynamics of acetylsalicylic acid $81 \mathrm{mg}$ with or without esomeprazole $20 \mathrm{mg}$ in health volunteers. Am J Cardiovasc Drugs. 2012;12(4):217-224.
34. Yeomans N, Lanas A, Labenz J, et al. Efficacy of esomeprazole (20 mg once daily) for reducing the risk of gastrointestinal ulcers associated with continuous use of low-dose aspirin. Am J Gastroenterol. 2008; 103(10):2465-2473.

35. Scheiman JM, Devereaux PJ, Herlitz J, et al. Prevention of peptic ulcers with esomeprazole in patients at risk of ulcer development treated with low-dose acetylsalicylic acid: a randomized, controlled trial (OBERON). Heart. 2011;97(10):797-802.

36. Yang YX, Lewis JD, Epstein S, Metz DC. Long-term proton pump inhibitor therapy and risk of hip fracture. JAMA. 2006;296(24):2947-2953.

37. Gray SL, LaCroix AZ, Larson J, et al. Proton pump inhibitor use, hip fracture and change in bone mineral density in postmenopausal women: results from the Women's Health Initiative. Arch Intern Med. 2010;170(9):765-771.

38. Roux C, Briot K, Gossec L, et al. Increase in vertebral fracture risk in postmenopausal women using omeprazole. Calcif Tissue Int. 2009;84(1):13-19.

39. Khalili H, Huang ES, Jacobson BC, Camargo CA Jr, Feskanich D, Chan AT. Use of proton pump inhibitors and risk of hip fracture in relation to dietary and lifestyle factors: a prospective cohort study. $B M J$. 2012;344:e372.

40. Yu EW, Bauer SR, Bain PA, Bauer DC. Proton pump inhibitors and risk of fractures: a meta-analysis of 11 international studies. Am J Med. 2011;124(6):519-526.

41. Aseeri M, Schroeder T, Kramer J, Zackula R. Gastric acid suppression by proton pump inhibitors as a risk factor for Clostridium difficileassociated diarrhea in hospitalized patients. Am J Gastroenterol. 2008;103(9):2308-2313.

42. Loo VG, Bourgault AM, Poirier L, et al. Host and pathogen factors for Clostridium difficile infection and colonization. $N$ Engl J Med. 2011;365(18):1693-1703.

43. Madanick RD. Proton pump inhibitor side effects and drug interactions: much ado about nothing? Cleve Clin J Med. 2011;78(1):39-49.

44. Ali T, Roberts DN, Tierney WM. Long-term safety concerns with proton pump inhibitors. Am J Med. 2009;122(10):896-903.

45. Chapman DB, Rees CJ, Lippert D, Sataloff RT, Wright SC Jr. Adverse effects of long-term proton pump inhibitor use: a review for the otolaryngologist. J Voice. 2011;25(2):236-240.

46. Andersson T, Hassan-Alin M, Hasselgren G, Röhss K. Drug interaction studies with esomeprazole, the (S)-isomer of omeprazole. Clin Pharmacokinet. 2001;40(7):523-537.

47. O’Donoghue ML, Braunwald E, Antman EM, et al. Pharmacodynamic effect and clinical efficacy of clopidogrel and prasugrel with and without a proton pump inhibitor: an analysis of two randomized trials. Lancet. 2009;374(9694):989-997.

48. Bhatt DL, Cryer BL, Constant CF, et al; COGENT Investigators. Clopidogrel with or without omeprazole in coronary artery disease. N Engl J Med. 2010;363(20):1909-1917.

49. Ho PM, Maddox TM, Wang L, et al. Risk of adverse outcomes associated with comcomitant use of clopidogrel and proton pump inhibitors following acute coronary syndrome. JAMA. 2009;301(9):937-944.

50. US Food and Drug Administration [homepage on the Internet]. Information for healthcare professionals: update to the labeling of clopidogrel bisulfate (marketed as Plavix) to alert healthcare professionals about a drug interaction with omeprazole (marketed as Prilosec and Prilosec OTC). Silver Spring: US Food and Drug Administration; 2009. Available from: http://www.fda.gov/Drugs/DrugSafety/PostmarketDrug SafetyInformationforPatientsandProviders/DrugSafetyInformationfor HeathcareProfessionals/ucm190787.htm. Accessed February 2, 2013.

51. Focks JJ, Brouwer MA, van Oijen MG, Lanas A, Bhatt DL, Verheugt FW. Concomitant use of clopidogrel and proton pump inhibitors: impact on platelet function and clinical outcomes-a systematic review. Heart. 2013;99(8):520-527.

52. AstraZeneca Pharmaceuticals. Esomeprazole (Nexium) US Prescribing Information. Wilmington: AstraZeneca Pharmaceuticals LP; 2012. Available from: http://www1.astrazeneca-us.com/pi/Nexium.pdf. Accessed February 3, 2013. 
53. Earnshaw SR, Scheiman J, Fendrick AM, McDade C, Pignone M. Costutility of aspirin and proton pump inhibitors for primary prevention. Arch Intern Med. 2011;171(3):218-225.

54. Saini SD, Schoenfeld P, Fendrick AM, Scheiman J. Cost-effectiveness of proton pump inhibitor cotherapy in patients taking long-term, lowdose aspirin for secondary cardiovascular prevention. Arch Intern Med. 2008;168(15):1684-1690.
55. Saini SD, Fendrick AM, Scheiman JM. Cost-effectiveness analysis: cardiovascular benefits of proton pump inhibitor co-therapy in patients using aspirin for secondary prevention. Aliment Pharmacol Ther. 2011; 34(2):243-251.

56. American Diabetes Association. Standards of medical care in diabetes - 2011. Diabetes Care. 2011;34(Suppl 1):S11-S61.

\section{Publish your work in this journal}

Vascular Health and Risk Management is an international, peerreviewed journal of therapeutics and risk management, focusing on concise rapid reporting of clinical studies on the processes involved in the maintenance of vascular health; the monitoring, prevention and treatment of vascular disease and its sequelae; and the involvement of metabolic disorders, particularly diabetes. This journal is indexed on PubMed Central and MedLine. The manuscript management system is completely online and includes a very quick and fair peer-review system, which is all easy to use. Visit http://www.dovepress.com/ testimonials.php to read real quotes from published authors.

Submit your manuscript here: http://www.dovepress.com/vascular-health-and-risk-management-journal 